\title{
BMJ Open A cross-sectional multicentre study of cardiac risk score use in the management of unstable angina and non-ST-elevation myocardial infarction
}

\author{
Josien Engel, ${ }^{1}$ Ineke van der Wulp, ${ }^{1}$ Martine de Bruijne, ${ }^{1}$ Cordula Wagner ${ }^{1,2}$
}

To cite: Engel J, van der Wulp I, de Bruijne M, et al. A cross-sectional multicentre study of cardiac risk score use in the management of unstable angina and non-STelevation myocardial infarction. BMJ Open 2015;5: e008523. doi:10.1136/ bmjopen-2015-008523

- Prepublication history for this paper is available online. To view these files please visit the journal online (http://dx.doi.org/10.1136/ bmjopen-2015-008523).

Received 16 April 2015 Revised 16 July 2015 Accepted 24 July 2015

\section{CrossMark}

${ }^{1}$ Department of Public and Occupational Health, EMGO Institute for Health and Care Research, VU University Medical Center, Amsterdam, The Netherlands

${ }^{2}$ NIVEL, Netherlands Institute for Health Services Research, Utrecht, The Netherlands

Correspondence to

Josien Engel;

j.engel1@vumc.nl

\section{ABSTRACT}

Objectives: Quantitative risk assessment in unstable angina (UA) and non-ST-elevation myocardial infarction (NSTEMI), by using cardiac risk scores, is recommended in international guidelines. However, a gap between recommended care and actual practice exists, as these instruments seem underused in practice. The present study aimed to determine the extent of cardiac risk score use and to study factors associated with lower or higher cardiac risk score use.

Setting: 13 hospitals throughout the Netherlands. Participants: A retrospective chart review of 1788 charts of patients with UA and NSTEMI, discharged in 2012.

Primary and secondary outcomes: The extent of cardiac risk score use reflected in a documented risk score outcome in the patient's chart. Factors associated with cardiac risk score use determined by generalised linear mixed models.

Results: In 57\% ( $\mathrm{n}=1019)$ of the charts, physicians documented the use of a cardiac risk score. Substantial variation between hospitals was observed (16.7-87\%), although this variation could not be explained by the presence of on-site revascularisation facilities or a hospitals' teaching status. Obese patients $(\mathrm{OR}=1.49 ; \mathrm{Cl}$ $95 \% 1.03$ to 2.15 ) and former smokers (OR=1.56; $\mathrm{Cl}$ $95 \% 1.15$ to 2.11 ) were more likely to have a cardiac risk score documented. Risk scores were less likely to be used among patients diagnosed with UA $(O R=0.60$; $\mathrm{Cl} 95 \% 0.46$ to 0.77 ), in-hospital resuscitation (OR=0.23; $\mathrm{Cl} 95 \% 0.09$ to 0.64), in-hospital heart failure $(O R=0.46 ; \mathrm{Cl} 95 \% 0.27$ to 0.76$)$ or tachycardia (OR=0.45; Cl 95\% 0.26 to 0.75 ).

Conclusions: Despite recommendations in cardiac guidelines, the use of cardiac risk scores has not been fully implemented in Dutch practice. A substantial number of patients did not have a cardiac risk score documented in their chart. Strategies to improve cardiac risk score use should pay special attention to patient groups in which risk scores were less often documented, as these patients may currently be undertreated.

\section{BACKGROUND}

In the past decade mortality rates in acute coronary syndromes, including unstable

\section{Strengths and limitations of this study}

- This multicentre study is the first to provide thorough insight into the extent of cardiac risk score use in clinical practice by reviewing patient charts in 13 hospitals throughout the Netherlands.

- Generalised linear mixed models were used to study hospital-related and patient-related factors associated with lower or higher cardiac risk score use.

- The results can serve as a basis for future improvement initiatives aimed to enhance cardiac risk score use in practice, by tailoring strategies to patient groups in which risk scores are less often documented.

- It was not possible to study associations between the extent of cardiac risk score use and the occurrence of adverse patient outcomes (eg, death) due to practical constraints.

- Using retrospective review of medical charts as the underlying method of data collection made it impossible to determine the actual influence of cardiac risk score use on clinical decisionmaking of healthcare providers involved in the management of patients with unstable angina or non-ST-elevation myocardial infarction.

angina (UA) and non-ST-elevation myocardial infarction (NSTEMI), decreased significantly due to substantial improvements in treatment possibilities. ${ }^{1} 2$ Despite these advancements, these conditions still account for a large part of the annual deaths worldwide and are expected to be the leading cause of death and to account for the largest disease burden worldwide by $2020-2030 .^{3-5}$ Part of these deaths may be prevented, as it has previously been reported that a substantial number of patients were not treated according to the current standards of care. ${ }^{6-8}$ Patients with diabetes mellitus, renal insufficiency, signs of heart failure and patients aged 75 years or older were often 
neglected guideline recommended care. ${ }^{6}$ On the other hand, patients presenting to academic hospitals and to hospitals with revascularisation facilities onsite (eg, percutaneous coronary intervention (PCI) or coronary artery bypass grafting $(\mathrm{CABG})$ ) were more often treated in accordance to the guidelines. ${ }^{7}{ }^{9}$ Patients diagnosed with UA or NSTEMI can be treated with medication or invasive procedures such as PCI or CABG. According to international cardiac guidelines, the decision to treat such patients with one or the other may be made on the basis of a quantitative assessment of the patient's risk of reinfarction or death. ${ }^{10-12}$ To assist clinicians in identifying patients at high risk of adverse cardiac events that would benefit most from invasive therapies, several instruments have been developed. ${ }^{10-12}$ The GRACE (Global Registry of Acute Coronary Events), ${ }^{13}{ }^{14}$ TIMI (Thrombolysis in Myocardial Infarction), ${ }^{15}$ FRISC (fast revascularisation in instability in coronary disease), ${ }^{16}$ PURSUIT (Platelet glycoprotein IIb/IIIa in Unstable angina: Receptor Suppression Using Integrilin) ${ }^{17}$ and HEART risk scores ${ }^{18}$ are examples of validated cardiac risk scoring instruments. In estimating risk, these instruments incorporate and combine several diagnostic elements including a patient's history, biomarkers and ECG findings, and can be used in the emergency department or coronary care unit. The predictive validity of these instruments was reported to be good. ${ }^{16} 1920$ Previous research found that cardiac risk scores were effective in identifying patients at high risk for cardiac events. ${ }^{21} 22$ However, a gap between recommended care in the guidelines and actual practice seems to exist, as it has been suggested before that cardiac risk scores are not routinely used in clinical practice. ${ }^{21} 2324$ This possibly contributes to perpetuating the 'treatment risk paradox', in which patients with low risk of adverse cardiac events, opposite to cardiac guideline recommendations, were more likely to receive invasive cardiac treatment compared with high-risk patients. ${ }^{6}{ }^{25-30}$ Prior to creating future improvement initiatives aimed to increase cardiac risk score use, knowledge about the extent of this gap and associated factors is necessary. The present study, therefore, aimed to determine the extent of cardiac risk score use in Dutch clinical practice and to study factors associated with lower or higher cardiac risk score use.

\section{METHODS}

This study concerns a cross-sectional multicentre study. A detailed description of the study protocol has been published previously. ${ }^{31}$ Where required, approval from hospitals' local ethics board was obtained.

\section{Setting}

In 2008, all hospitals in the Netherlands committed themselves to the implementation of a quality improvement programme aimed to enhance patient safety in Dutch hospitals. The programme comprised several themes, including the theme 'Optimal care for Acute
Coronary Syndromes' which, among other things, aimed to increase the application of cardiac risk scores in clinical practice. ${ }^{32}$ A random selection of 40 hospitals participated voluntarily in the evaluation of the nationwide quality improvement programme. By a multistage random sampling procedure, initially 12 hospitals were selected from the pool of 40 hospitals to participate in the current study (ie, evaluation of cardiac risk score use). Three PCI-capable hospitals declined participation, for which three additional PCI-capable hospitals were selected. Additionally, one hospital was selected to obtain optimal diversity in onsite revascularisation facilities and teaching status. The final sample consisted of 13 hospitals, of which 2 university hospitals, 7 tertiary teaching hospitals and 4 general hospitals. Bed capacity in the hospitals varied between 200 and 1200 beds.

\section{Data collection}

The primary study outcome was the extent to which cardiac risk scores were used in the management of patients with UA and NSTEMI, reflected in a documented risk score outcome in the patient's chart. Data were collected monthly by means of retrospective chart review.

Potentially eligible charts were selected from the hospitals' billing system based on diagnostic-related group codes for UA and NSTEMI. All patients discharged in 2012, 18 years or older, with a diagnosis of UA or NSTEMI (as confirmed in the discharge letter) were considered for inclusion. Charts of patients who were transferred in from another hospital were excluded, as these patients were initially treated elsewhere and therefore the necessary data could not be obtained. In addition, charts of patients who provided insufficient information regarding the discharge diagnosis, who were hospitalised for an elective procedure, or who had an underlying illness or condition, other than a coronary stenosis, causing UA or NSTEMI (eg, anaemia) were excluded.

Charts of patients were selected per month in chronological order of discharge, until the screening capacity of the chart abstractors was reached. Charts of potentially eligible patients were manually reviewed to confirm a discharge diagnosis of UA or NSTEMI. In case a patient's final discharge diagnosis was unclear, a physician of the cardiology department was consulted. The following patient-related and hospital-related information was registered on standardised data extraction forms: demographic characteristics, cardiac history, presence of cardiac risk factors, presenting symptoms, biochemical and ECG findings and treatment practices. In addition, information regarding cardiac risk score use was registered, including the use of a validated risk score (yes/no), date of application, type of risk score used and risk score outcome and classification. Besides patient-related information, the following hospital factors were registered: teaching status (yes/no) and the presence of onsite revascularisation facilities. 
The data were entered into a database using fixed entry fields (BLAISE V.4.7, Statistics Netherlands) and data reliability checks were conducted. To ensure reliable data extraction, more than 5\% (103/1933) of the charts were screened by two chart abstractors independently. The total percentage of agreement between these abstractors was $95.1 \%$, and ranged for the variables of interest (table 1) between $80.6 \%$ (ECG findings) and $100 \%$ (gender), indicating good to excellent data reliability.

\section{Missing data}

In total, $1.5 \%$ of the values in the data set were missing, ranging from $0.1 \%$ to $22 \%$ per variable. Eleven variables had no missing values, including cardiac risk score use. Despite the small amount of missing data and the spread of missing data in the data set, a complete case analysis would have led to a large loss of information and power. Therefore, missing values were imputed using a multiple imputation procedure following the approach of van Buuren and Groothuis-Oudshoorn, ${ }^{33}$ resulting in five imputed data sets. In imputing missing values, it was assumed that the data were missing at random. The estimated values were corrected for the variables 'hospital' and 'cardiac risk score use' as these variables were of primary interest in the analyses. By means of the Kolmogorov-Smirnov test, and density and residual plots, it was determined whether the missing at random assumption was sustainable and the imputed values were plausible. In addition, a sensitivity analysis was conducted by comparing the results from the analyses of the imputed data with the results of a complete case analysis. Between these models, only small differences were found. The missing value analyses and their imputations were conducted in R (V.3.0.2 for Microsoft Windows) using the MICE package. ${ }^{33} 34$

\section{Data analysis}

Sample characteristics were calculated using descriptive statistics, and included frequencies and percentages for categorical variables, and means and SDs for continuous variables. Associations of independent variables (table 1) with the use of cardiac risk scores (yes/no) were studied with a generalised linear mixed model (GLMM), taking into account the clustering of data within hospitals. ${ }^{35}$ ORs, that are based on median probabilities over hospitals for cardiac risk score use, are presented. To facilitate interpretation, relevant explanatory variables were transformed into categorical variables (ie, age, heart rate and systolic blood pressure). Furthermore, month of discharge was represented by a categorical variable with 12 levels in every model, to account for the fact that chart abstractors were present on hospital departments to abstract data. In univariate analyses, associations between cardiac risk score use and the independent variables were tested. All variables with a significance level of $\mathrm{p} \leq 0.15$ were entered in a multivariable model. Variables significantly associated $(p \leq 0.05)$ with cardiac risk score use in the multivariable model were considered important in predicting risk score adherence. In addition, based on previous literature two factor interactions with onsite revascularisation options, teaching status, age and gender were tested. All analyses were conducted in $\mathrm{R}$ for windows (V.3.0.2) using the package lme4 on pooled data of five imputed data sets. ${ }^{34}$ The script of the pool function in MICE was rewritten for pooling GLMM models.

\section{RESULTS}

\section{Study population}

A total of 1933 charts of patients with a confirmed diagnosis of UA or NSTEMI were screened. Of these, 145 $(7.5 \%)$ were excluded from the study as these

Table 1 Independent variables in generalised linear mixed model

\begin{tabular}{|c|c|c|}
\hline Patient characteristics & Patient characteristics & Patient characteristics \\
\hline $\begin{array}{l}\text { Demographics } \\
\text { Age } \\
\text { Presenting factors } \\
\text { Heart rate } \\
\text { Systolic blood pressure } \\
\text { Resuscitation at admission } \\
\text { Cardiogenic shock } \\
\text { In-hospital heart failure } \\
\text { ST deviations on ECG } \\
\text { Discharge diagnosis } \\
\text { UA }\end{array}$ & $\begin{array}{l}\text { Cardiac history } \\
\text { - Coronary artery disease } \\
\text { Peripheral vascular disease } \\
\text { - } \text { (Unstable) angina pectoris } \\
\text { Acute myocardial infarction } \\
\text { Previous CABG } \\
\text { Previous PCI } \\
\text { Hospital characteristics } \\
\text { - Presence of revascularisation options } \\
\text { - Teaching status }\end{array}$ & $\begin{array}{l}\text { Risk factors } \\
\text { Diabetes mellitus } \\
\text { Hypertension } \\
\text { Renal failure } \\
\text { Chronic heart failure } \\
\text { Positive family history } \\
\text { Smoking } \\
\text { Former smoker } \\
\text { Hypercholesterolaemia* } \\
\text { Obesity }(B M I>30) \\
\text { Coronary stenosis } \geq 50 \% \text { (in history) }\end{array}$ \\
\hline
\end{tabular}


concerned patients transferred from one hospital to another, leaving 1788 patients for further analysis (figure 1). The majority $(62.6 \%)$ of these patients had a discharge diagnosis of NSTEMI (table 2). Males accounted for $66.9 \%$ of the patients, and more than a third $(35.9 \%)$ of the patients were aged 75 years or older. Three-quarters $(75.3 \%)$ of the total population underwent coronary catheterisation. The average length of hospital stay was 5 days $(\mathrm{SD}=4.97)$.

\section{Cardiac risk score use}

In 57\% of the patient charts, a cardiac risk score was documented, though substantial variation between hospitals was observed, that is, $16.7-87 \%$ (table 3 ). Six out of the 13 hospitals used more than one risk scoring instrument to calculate a risk score, being the following: GRACE (12/13 hospitals), TIMI (3/13 hospitals), FRISC $(1 / 13$ hospitals) and the HEART risk score $(6 / 13$ hospitals; table 3). The variance component for the random hospital effect in the GLMM ranged between 1.29 and 1.31 in the five imputed data sets, confirming the great variety between hospitals in the use of cardiac risk scores. When, for instance, the effects for two hospitals are equal to the 5th and 95th centiles of the normal distribution with variance 1.3 for hospital effects, the OR of one hospital relative to the other for cardiac risk score use is 42.6 .

In univariate analyses, 15 patient-related factors were significantly $(\mathrm{p} \leq 0.15)$ associated with cardiac risk score use (table 4). No significant associations with hospitalrelated factors were found (teaching status $\mathrm{p}=0.25$, onsite revascularisation facilities $\mathrm{p}=0.67)$. In multivariable analyses, patients with obesity $(\mathrm{OR}=1.49 ; 95 \% \mathrm{CI}$ 1.03 to $2.15 ; \mathrm{p}=0.04)$ and former smokers $(\mathrm{OR}=1.56$; $95 \%$ CI 1.15 to $2.11 ; \mathrm{p} \leq 0.01$ ) were more likely to have a cardiac risk score documented. Conversely patients with
Figure 1 Inclusion and exclusion procedure of chart selection and screening (NSTEMI, non-ST-elevation myocardial infarction; UA, unstable angina).

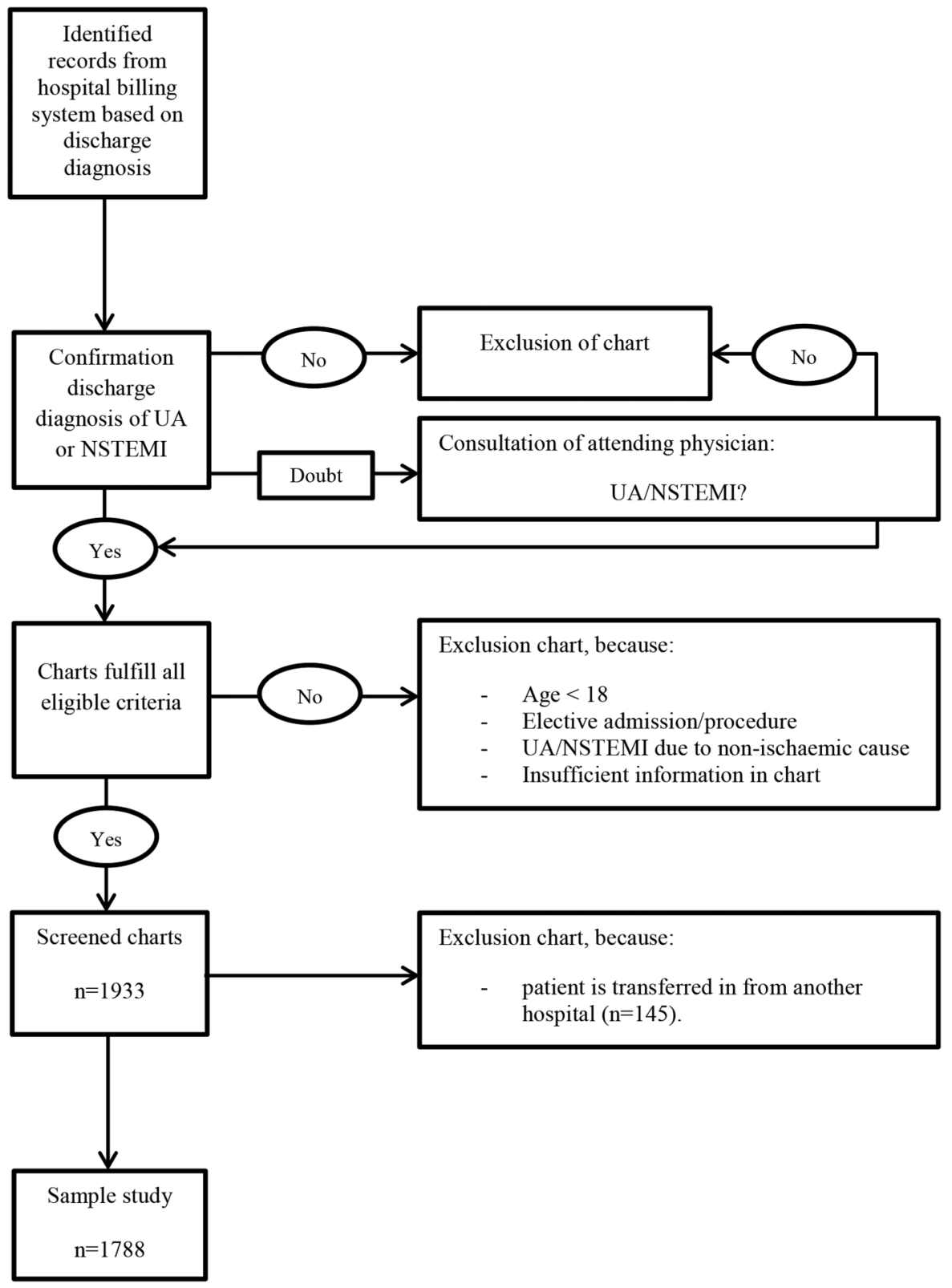


Table 2 Patient and admission characteristics of study sample

\begin{tabular}{|c|c|}
\hline $\begin{array}{l}\text { Baseline characteristics (pooled data) } \\
(n=1788)\end{array}$ & $n(\%)^{*}$ \\
\hline Age $(<75$ years $)$ & $1146(64.1)$ \\
\hline Gender (male) & $1196(66.9)$ \\
\hline Discharge diagnoses (NSTEMI) & $1119(62.6)$ \\
\hline Length of hospital stay (days) (mean \pm SD) & $5 \pm 4.97$ \\
\hline \multicolumn{2}{|l|}{ Systolic blood pressure $(\mathrm{mm} \mathrm{Hg})$} \\
\hline High $(\geq 160)$ & $552(30.9)$ \\
\hline Normal to slightly elevated $(81-159)$ & $1236(69.1)$ \\
\hline Low $(\leq 80)$ & $0(0)$ \\
\hline \multicolumn{2}{|l|}{ Heart rate $(\mathrm{bpm})$} \\
\hline Tachycardia $(\geq 110)$ & $103(5.8)$ \\
\hline Normal (51-109) & $1634(91.4)$ \\
\hline Bradycardia $(\leq 50)$ & $51(2.8)$ \\
\hline Resuscitation at admission & $33(1.9)$ \\
\hline Cardiogenic shock & $7(0.4)$ \\
\hline In-hospital heart failure & $103(5.8)$ \\
\hline ST deviations on ECG & $810(45.3)$ \\
\hline History of coronary artery disease & $252(14.1)$ \\
\hline History of peripheral vascular disease & $131(7.3)$ \\
\hline Previous (U)A & $432(24.1)$ \\
\hline Previous MI & 499 (27.9) \\
\hline Previous $\mathrm{PCl}$ & $523(29.3)$ \\
\hline Previous CABG & $289(16.2)$ \\
\hline $\begin{array}{l}\mathrm{MI} \text { or } \mathrm{PCI} / \mathrm{CABG} 6 \text { months prior to } \\
\text { admission }\end{array}$ & $125(7)$ \\
\hline Diabetes mellitus & $451(25.2)$ \\
\hline Hypertension & $936(52.4)$ \\
\hline Renal failure & $88(4.9)$ \\
\hline Chronic heart failure & $101(5.7)$ \\
\hline Hypercholesterolaemia† & $986(55.1)$ \\
\hline Obesity $(\mathrm{BMI}>30)$ & $203(11.3)$ \\
\hline Smoking & $427(23.9)$ \\
\hline Former smoker & $350(19.6)$ \\
\hline Coronary stenosis ( $\geq 50 \%)$ & $192(10.8)$ \\
\hline Positive family history & $618(34.6)$ \\
\hline Coronary catheterisation & $1346(75.3)$ \\
\hline \multicolumn{2}{|l|}{ Management strategy } \\
\hline Pharmacological therapy & $754(42.2)$ \\
\hline (scheduled) $\mathrm{PCl}$ & $846(47.3)$ \\
\hline (scheduled) CABG & $188(10.5)$ \\
\hline \multicolumn{2}{|c|}{$\begin{array}{l}\text { *Data are presented in } n(\%) \text {, unless stated otherwise. } \\
\text { †Defined as statin use prior to admission, or described in patients } \\
\text { history (elevated cholesterol levels, hyperlipidaemia or } \\
\text { hypercholesterolaemia). } \\
\text { BMI, body mass index; CABG, coronary artery bypass grafting; } \\
\text { MI, myocardial infarction; PCl, percutaneous coronary } \\
\text { intervention; (U)A, (unstable)angina. }\end{array}$} \\
\hline
\end{tabular}

UA ( $\mathrm{OR}=0.60 ; 95 \%$ CI 0.46 to $0.77 ; \mathrm{p} \leq 0.01)$, in-hospital heart failure $(\mathrm{OR}=0.46 ; 95 \%$ CI 0.27 to $0.76 ; \mathrm{p} \leq 0.01)$, tachycardia $(\mathrm{OR}=0.45 ; 95 \%$ CI 0.26 to $0.75 ; \mathrm{p} \leq 0.01)$ or who had been resuscitated at admission $(\mathrm{OR}=0.23 ; 95 \%$ CI 0.09 to $0.64 ; \mathrm{p} \leq 0.01$ ) were less likely to have a cardiac risk score documented (table 4 ).

\section{Interactions}

Besides the interactions with onsite revascularisation options, teaching status, age and gender, it was decided to also test whether interactions with former smoker were present. This, because an unexpected significant association between former smoker and risk score use was found. Significant interactions were found between the variables former smoker and discharge diagnosis $(\mathrm{p}=0.03)$, age and previous PCI $(\mathrm{p}=0.02)$, age and in-hospital heart failure $(\mathrm{p}=0.04)$, age and history of peripheral artery disease $(p=0.03)$, and age and heart rate $(\mathrm{p}=0.04$; table 5$)$.

Looking at the interaction effects with age, it was found that patients aged 75 years or over presenting with a previous PCI had a higher odds of cardiac risk score documentation compared with patients without a previous PCI (OR=1.53; 95\% CI 1.00 to 2.34; $\mathrm{p}=0.05)$. In contrast, older patients were less likely to have a cardiac risk score documented in case they presented with heart failure ( $\mathrm{OR}=0.29 ; 95 \%$ CI 0.14 to $0.57 ; \mathrm{p}<0.001)$, with a history of peripheral artery disease $(\mathrm{OR}=0.47 ; 95 \%$ CI 0.24 to $0.91 ; \mathrm{p}=0.02)$ or with tachycardia $(\mathrm{OR}=0.20 ; 95 \%$ CI 0.08 to $0.52 ; \mathrm{p} \leq 0.001)$.

\section{DISCUSSION}

This study aimed to provide insight in the extent of cardiac risk score use in Dutch hospitals as recommended by international cardiac guidelines. In addition, associations with patient-related and hospital-related factors were studied. Substantial variation between hospitals' cardiac risk score use was observed, with in approximately $40 \%$ of patient charts a cardiac risk score was not documented. Several patient-related factors including a diagnosis of UA, the presence of in-hospital heart failure, tachycardia and resuscitation at admission were associated with a lower likelihood of cardiac risk score use. Although evidence is not conclusive, the probability of cardiac risk score use was often lower in older patients ( $\geq 75$ years) with additional conditions, such as in-hospital heart failure, a history of peripheral artery disease or tachycardia.

Previous studies also reported advanced age, heart failure and tachycardia as important predictors of lower guideline adherence in patients with acute coronary syndromes. ${ }^{6}{ }^{36-41}$ Moreover, several of these studies also reported a decreased likelihood of survival. ${ }^{37} 38 \quad 40$ Implying that patients at high risk for adverse cardiac outcomes are less likely to receive guideline recommended care. However, according to the European guidelines, these high-risk subgroups of patients benefit most from early invasive treatments. ${ }^{10}$ It may, however, be discussed to what degree an invasive treatment may be desired in these high-risk subgroups of patients. Also, it could be questionable to what degree risk stratification using a cardiac risk score adds value in deciding on the treatment for these patients, for example, in the case of resuscitation the decision for a certain procedure may be evident. The European Society of Cardiology guidelines, however, do not take these circumstances into account and recommend to estimate risk levels with a 
Table 3 Adherence to cardiac risk score use per hospital (pooled data)

\begin{tabular}{|c|c|c|c|c|c|c|c|c|}
\hline \multirow{2}{*}{$\begin{array}{l}\text { Hospital } \\
\text { ID* }\end{array}$} & \multirow{2}{*}{$\begin{array}{l}\text { Teaching } \\
\text { status }\end{array}$} & \multirow{2}{*}{$\begin{array}{l}\text { PCI/CABG } \\
\text { options }\end{array}$} & \multirow{2}{*}{$\begin{array}{l}\text { Screened } \\
\text { charts, n† }\end{array}$} & \multirow{2}{*}{$\begin{array}{l}\text { Risk score use, } n \\
(\%) \S\end{array}$} & \multicolumn{4}{|c|}{ Type of risk score used } \\
\hline & & & & & GRACE & TIMI & FRISC & HEART \\
\hline 1 & No & No & 84 & $14(16.7)$ & $\mathrm{X}$ & - & - & - \\
\hline 2 & Yes & Yes & 109 & $22(20.2)$ & $\mathrm{X}$ & $x$ & - & - \\
\hline 3 & No & No & 110 & $26(23.6)$ & $\mathrm{X}$ & - & - & - \\
\hline 4 & No & No & 171 & 57 (33.3) & - & - & - & $x$ \\
\hline 5 & Yes & Yes & 132 & $46(34.8)$ & $x$ & - & - & $x$ \\
\hline 6 & Yes & No & 53 & $19(35.8)$ & $\mathrm{X}$ & - & - & - \\
\hline 7 & Yes & Yes & 145 & $79(54.5)$ & $\mathrm{X}$ & - & $x$ & $x$ \\
\hline 8 & Yes & Yes & 182 & 108 (59.3) & $x$ & - & - & $x$ \\
\hline 9 & Yes & Yes & 96 & 68 (70.8) & $x$ & - & - & - \\
\hline 10 & Yes & Yes & 140 & 107 (76.4) & $x$ & - & - & $x$ \\
\hline 11 & Yes & Yes & 108 & 87 (80.6) & $X$ & $x$ & - & $x$ \\
\hline 12 & No & No & 205 & $166(81.0)$ & $x$ & $x$ & - & - \\
\hline 13 & Yes & No & 253 & 220 (87.0) & $x$ & - & - & - \\
\hline Total & - & - & 1788 & 1019 (57\%) & - & - & - & - \\
\hline
\end{tabular}

${ }^{*}$ Ranging from lowest to highest scoring hospital.

†Large variation in screened patient charts per hospital is explained by differences in the amount of monthly admission for UA/NSTEMI. §Risk score use is represented by (one or more) documented risk score outcome(s) in the patient's chart.

ๆSeveral hospitals calculated more than one risk score per patient, using different risk scoring instruments.

CABG, coronary artery bypass grafting; FRISC, fast revascularisation in instability in coronary disease; GRACE, global registry of acute coronary events; PCI, percutaneous coronary intervention; TIMI, Thrombolysis in Myocardial Infarction.

cardiac risk scoring instrument for every patient suspected of UA/NSTEMI. ${ }^{10}$

Obese patients and former smokers were more likely to have a cardiac risk score documented. The association of former smoking and the use of a cardiac risk score, however, was unexpected and difficult to explain. There are no indications for partial confounding with other factors in the model as ORs for former smoker in

Table 4 Univariate and multivariable associations between risk score documentation in patient charts and hospital-related and patient-related factors (pooled data; $\mathrm{n}=1788$ ) $\dagger$

\begin{tabular}{|c|c|c|c|c|}
\hline & \multicolumn{2}{|c|}{ Univariate associations } & \multicolumn{2}{|c|}{ Multivariable associations } \\
\hline & OR (95\% Cl) & p Value & OR (95\% Cl) & p Value \\
\hline \multicolumn{5}{|l|}{ Hospital factors } \\
\hline Teaching status & 2.15 (0.59 to 7.85$)$ & 0.25 & NA & NA \\
\hline Onsite revascularisation facilities & $1.32(0.38$ to 4.60$)$ & 0.67 & NA & NA \\
\hline \multicolumn{5}{|l|}{ Patient factors $\ddagger$} \\
\hline Discharge diagnosis (reference NSTEMI) & 0.65 (0.52 to 0.83$)$ & $\leq 0.01^{\star \star}$ & 0.60 (0.46 to 0.77$)$ & $\leq 0.01^{\star *}$ \\
\hline Age (reference $<75$ years) & 0.76 (0.61 to 0.96$)$ & $0.02^{*}$ & 0.86 (0.67 to 1.11$)$ & 0.24 \\
\hline Resuscitation at admission & 0.25 (0.10 to 0.67$)$ & $\leq 0.01^{\star \star}$ & 0.23 (0.09 to 0.64$)$ & $\leq 0.01^{\star *}$ \\
\hline In-hospital heart failure & $0.38(0.24$ to 0.62$)$ & $\leq 0.01^{\star *}$ & $0.46(0.27$ to 0.76$)$ & $\leq 0.01^{* *}$ \\
\hline History of coronary artery disease & 0.65 (0.47 to 0.89$)$ & $\leq 0.01^{\star *}$ & 0.87 (0.59 to 1.27$)$ & 0.46 \\
\hline History of peripheral artery disease & $0.72(0.47$ to 1.09$)$ & 0.12 & 0.81 (0.53 to 1.26$)$ & 0.35 \\
\hline Previous (U)A & 0.83 (0.64 to 1.07$)$ & 0.15 & $1.00(0.75$ to 1.34$)$ & 0.98 \\
\hline Previous MI & 0.77 (0.61 to 0.98$)$ & $0.03^{*}$ & 0.89 (0.68 to 1.18$)$ & 0.43 \\
\hline Previous $\mathrm{PCl}$ & $0.83(0.65$ to 1.05$)$ & 0.13 & 1.07 (0.80 to 1.43$)$ & 0.66 \\
\hline Renal failure & 0.54 (0.33 to 0.90$)$ & $0.02^{*}$ & $0.72(0.42$ to 1.23$)$ & 0.23 \\
\hline Obesity (BMl>30) & 1.49 (1.05 to 2.13$)$ & $0.03^{*}$ & 1.49 (1.03 to 2.15$)$ & $0.04^{*}$ \\
\hline Smoking & $1.23(0.95$ to 1.60$)$ & 0.11 & $1.16(0.86$ to 1.55$)$ & 0.33 \\
\hline Former smoker & $1.48(1.12$ to 1.97$)$ & $\leq 0.01^{\star \star}$ & $1.56(1.15$ to 2.11$)$ & $\leq 0.01^{\star *}$ \\
\hline Coronary stenosis $(\geq 50 \%)$ & 0.65 (0.46 to 0.93$)$ & $0.02^{*}$ & 0.81 (0.54 to 1.22$)$ & 0.31 \\
\hline \multicolumn{5}{|l|}{ Heart rate (bpm) (reference normal) } \\
\hline Tachycardia & $0.46(0.28$ to 0.76$)$ & $\leq 0.01^{* *}$ & $0.45(0.26$ to 0.75$)$ & $\leq 0.01^{* *}$ \\
\hline Bradycardia & 0.85 (0.44 to 1.63$)$ & 0.62 & 0.92 (0.46 to 1.86$)$ & 0.82 \\
\hline \multicolumn{5}{|c|}{ 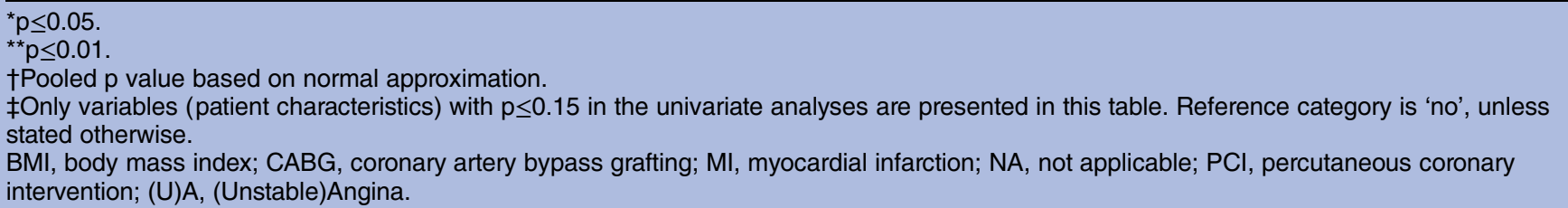 } \\
\hline
\end{tabular}


Table 5 Estimated ORs and $95 \%$ Cls for significant $(p \leq 0.05)$ interactions terms added to multivariable model of GLMM (pooled data) $\dagger$

\begin{tabular}{|c|c|c|c|}
\hline & OR & Cl $95 \%$ & p Value \\
\hline \multicolumn{4}{|l|}{ Former smoker ${ }^{*}$ discharge diagnosis } \\
\hline Discharge diagnosis (UA vs NSTEMI) within former smoker (no) & 0.52 & 0.40 to 0.69 & $<0.001^{* *}$ \\
\hline Discharge diagnosis (UA vs NSTEMI) within former smoker (yes) & 1.00 & 0.59 to 1.71 & 0.98 \\
\hline Former smoker (yes vs no) within discharge diagnosis (UA) & 2.28 & 1.43 to 3.61 & $<0.001^{\star *}$ \\
\hline Former smoker (yes vs no) within discharge diagnosis (NSTEMI) & 1.19 & 0.81 to 1.75 & 0.38 \\
\hline \multicolumn{4}{|l|}{ Age ${ }^{\star}$ previous $\mathrm{PCl}$} \\
\hline Age ( $\geq 75$ vs $<75$ years) within previous $\mathrm{PCl}$ (no) & 0.71 & 0.52 to 0.96 & $0.02^{*}$ \\
\hline Age ( $\geq 75$ vs $<75$ years) within previous $\mathrm{PCl}$ (yes) & 1.30 & 0.84 to 1.99 & 0.23 \\
\hline Previous $\mathrm{PCl}$ (yes vs no) within age ( $<75$ years) & 0.84 & 0.58 to 1.19 & 0.32 \\
\hline Previous $\mathrm{PCl}$ (yes vs no) within age ( $\geq 75$ years) & 1.53 & 1.00 to 2.34 & $0.05^{\star}$ \\
\hline \multicolumn{4}{|l|}{ Age*in-hospital heart failure } \\
\hline Age ( $\geq 75$ vs $<75$ years) within in-hospital heart failure (no) & 0.92 & 0.71 to 1.20 & 0.54 \\
\hline Age ( $\geq 75$ vs $<75$ years) within in-hospital heart failure (yes) & 0.32 & 0.12 to 0.85 & $0.02^{*}$ \\
\hline In-hospital heart failure (yes vs no) within age (<75 years) & 0.84 & 0.39 to 1.82 & 0.66 \\
\hline In-hospital heart failure (yes vs no) within age ( $\geq 75$ years) & 0.29 & 0.14 to 0.57 & $<0.001^{\star *}$ \\
\hline \multicolumn{4}{|l|}{ Age*history of peripheral artery disease } \\
\hline Age ( $\geq 75$ vs $<75$ years) within history of peripheral artery disease (no) & 0.93 & 0.72 to 1.21 & 0.60 \\
\hline Age ( $\geq 75$ vs $<75$ years) within history of peripheral artery disease (yes) & 0.34 & 0.14 to 0.80 & $0.01^{* *}$ \\
\hline History of peripheral artery disease (yes vs no) within age ( $<75$ years) & 1.28 & 0.70 to 2.32 & 0.42 \\
\hline History of peripheral artery disease (yes vs no) within age ( $\geq 75$ years) & 0.47 & 0.24 to 0.91 & $0.02^{*}$ \\
\hline \multicolumn{4}{|l|}{ Age*heart rate } \\
\hline Age ( $\geq 75$ vs $<75$ years) within heart rate (normal) & 0.91 & 0.70 to 1.18 & 0.47 \\
\hline Age ( $\geq 75$ vs $<75$ years) within heart rate (tachycardia) & 0.28 & 0.09 to 0.85 & $0.03^{*}$ \\
\hline Age ( $\geq 75$ vs $<75$ years) within heart rate (bradycardia) & 1.25 & 0.31 to 5.00 & 0.75 \\
\hline Heart rate (tachycardia vs normal) within age ( $<75$ years) & 0.67 & 0.34 to 1.30 & 0.23 \\
\hline Heart rate (bradycardia vs normal) within age ( $<75$ years) & 0.81 & 0.33 to 2.01 & 0.65 \\
\hline Heart rate (tachycardia vs normal) within age ( $\geq 75$ years) & 0.20 & 0.08 to 0.52 & $<0.001^{\star *}$ \\
\hline Heart rate (bradycardia vs normal) within age ( $\geq 75$ years) & 1.12 & 0.38 to 3.27 & 0.84 \\
\hline \multicolumn{4}{|c|}{$\begin{array}{l}{ }^{*} \mathrm{p} \leq 0.05 . \\
{ }^{* *} \leq 0.01 \text {. } \\
\dagger \text { †All four ORs per interaction term are presented in the table to form an impression of the nature of the interaction. For instance, two separate } \\
\text { ORs for former smoker no versus yes for patients with UA and NSTEMI and two separate ORs for UA versus NSTEMI for former smoker no } \\
\text { and yes. These four ORs are all shown, because when interaction between two factors is added to the model, the OR of one factor may } \\
\text { depend on the level of the other factor. } \\
\text { fp Value indicates if OR is significantly different from one. } \\
\text { GLMM, generalised linear mixed model; NSTEMI, non-ST-elevation myocardial infarction; PCI, percutaneous coronary intervention; UA, } \\
\text { unstable angina. }\end{array}$} \\
\hline
\end{tabular}

univariate and multivariable models are sizeable and similar. Possibly, former smoking is an alias for some other underlying and unknown variable. For instance, former smoking is seen as an indication of a former more high-risk lifestyle and that way affects judgement. Further research may provide more insight on this.

Another interesting finding, that contrasted the findings of previous studies, was that a hospitals' teaching status or the presence of onsite revascularisation facilities were not significantly associated with cardiac risk score use. ${ }^{7} 36$ These differences may be explained by the relatively small number of hospitals participating in the present study compared with previous studies. A large variation between hospitals in adherence scores regarding cardiac risk score use was found. The large component of variance, explained by the random hospital effect, suggests that cardiac risk score use in patients presenting with the same characteristics may heavily depend on which hospital the patient is presented in, and that other factors, beside a hospital's teaching status or onsite revascularisation facilities, are of influence. Common barriers in the implementation of cardiac risk scores, including the absence of necessary resources for implementation and cultural differences, may explain this substantial variation. ${ }^{42}$ Also, it has been suggested that physicians find the evidence underlying cardiac risk scores unconvincing. ${ }^{24}$ To increase the use of cardiac risk scores in clinical practice several implementation strategies, which pay explicit attention to patients with suspected UA, may be employed. A recent improvement initiative in the USA for instance, in which continuous education was the primary intervention, led to a significant increase in cardiac risk score documentation in patients with UA and NSTEMI. ${ }^{43}$ The use of continuous education has proven to be effective in achieving change in practice, however, it is recommended to also take into account facilitating factors and barriers on a patient, provider and organisational level. ${ }^{44}$ Therefore, further research is needed to carefully understand factors that explain the variation between hospitals' cardiac risk score use. 


\section{Study limitations}

Several limitations potentially affect the interpretation of the results of this study.

First, the use of cardiac risk scores was measured by screening charts on the documentation of a cardiac risk score. As a result, it is unknown to what degree a cardiac risk score influenced physicians' decision-making regarding appropriate management strategies. However, it is plausible that when a cardiac risk score was documented, it was also used in practice.

Second, four predictors reported in previous studies of risk score use, that is, aspirin use prior to admission, creatinine level, troponin level and biomarkers, were not considered in the present study. These data could not be abstracted reliably. As a result, the precision of the model reported in this study might be smaller compared with other studies. In addition, it was not possible to reliably extract at what time point a risk score was recorded. The time registered in the patient's file was often imprecise (ie, time was entered retrospectively and did not represent the actual time point at which the risk score was used) or lacking. Making it impossible to provide any additional contextual information regarding the use of cardiac risk scores in clinical practice.

Third, in two hospitals, the method of selection of patient charts differed, as in these hospitals it was not possible to select patients based on the hospital's billing system. This could have influenced the selection of patients. However, their effects may be limited as it appeared that the random effects of these two hospitals were well in range with those of the other hospitals.

Fourth, it was not possible to extract all data from the charts at one time point per hospital. Therefore, monthly data collection visits were deemed necessary. For this reason, the reported associations were corrected for month of discharge. However, the frequent presence of the researchers onsite may have led to more awareness of the healthcare providers using cardiac risk scores, and as a result have higher adherence scores than hospitals not participating in the evaluation of the quality improvement programme. This overestimation of adherence rates can also be a result of the fact that the evaluation of the improvement programme took place in a cohort of highly motivated hospitals, as they all voluntarily agreed to participate.

Finally, three of the randomly selected hospitals declined participation in this study, which may have introduced selection bias. Hospitals that declined participation were possibly lagging behind in implementation. The actual use of cardiac risk scores in practice might therefore be even lower than estimated in this paper.

\section{CONCLUSIONS}

The results of the present study indicate that cardiac risk scores have not been fully implemented in Dutch clinical practice, as a substantial number of patients had no risk score documented in their chart. The large variation between hospitals could not be explained by the presence of onsite revascularisation facilities or a hospitals' teaching status, as well as by several patient-related factors that were associated with higher or lower usage of cardiac risk scores in clinical practice. It is recommended that further research should focus first on explanatory factors for differences between hospitals, which could provide a basis for future improvement initiatives in which strategies are targeted towards patient groups in which risk scores were less often documented, as these patients may currently be undertreated.

Acknowledgements The authors would like to thank Marie-Julie Heeren, Felix van Urk, Suzanne Vonk and Rixt Zuidema for their support in data collection.

Contributors All authors made substantial contributions to conception and design of the study. JE carried out data collection, performed statistical analysis, and drafted the manuscript, and prepared the manuscript for publication. IvdW provided substantial support in imputation of data and statistical analysis. IvdW, MdB and CW made substantial contributions to interpretation of the data and revised the manuscript critically for important intellectual content. All authors read and approved the final manuscript.

Funding The study was funded by the Dutch Ministry of Public health, Welfare and Sports

Competing interests None declared.

Ethics approval Medical ethical committee of the VU University Medical Center Amsterdam.

Provenance and peer review Not commissioned; externally peer reviewed.

Data sharing statement No additional data are available.

Open Access This is an Open Access article distributed in accordance with the Creative Commons Attribution Non Commercial (CC BY-NC 4.0) license, which permits others to distribute, remix, adapt, build upon this work noncommercially, and license their derivative works on different terms, provided the original work is properly cited and the use is non-commercial. See: http:// creativecommons.org/licenses/by-nc/4.0/

\section{REFERENCES}

1. Fox KA, Steg PG, Eagle KA, et al. GRACE Investigators. Decline in rates of death and heart failure in acute coronary syndromes, 19992006. JAMA 2007;297:1892-900.

2. Yeh RW, Sidney S, Chandra M, et al. Population trends in the incidence and outcomes of acute myocardial infarction. $N$ Engl $J$ Med 2010;362:2155-65.

3. Lopez AD, Murray CJ. The global burden of disease. A comprehensive assessment of mortality and disability from diseases, injuries and risk factors in 1990 and projected to 2020. Cambridge, MA: Harvard University Press, 1996.

4. Murray CJ, Lopez AD. Alternative projections of mortality and disability by cause 1990-2020: Global Burden of Disease Study. Lancet 1997;349:1498-504.

5. Mathers CD, Loncar D. Projections of global mortality and burden of disease from 2002 to 2030. PLoS Med 2006;3:e442.

6. Roe MT, Peterson ED, Newby LK, et al. The influence of risk status on guideline adherence for patients with non-ST-segment elevation acute coronary syndromes. Am Heart J 2006;151:1205-13.

7. Peterson ED, Roe MT, Mulgund J, et al. Association between hospital process performance and outcomes among patients with acute coronary syndromes. JAMA 2006;295:1912-20.

8. Gulati M, Patel S, Jaffe AS, et al. Impact of contemporary guideline compliance on risk stratification models for acute coronary syndromes in The Registry of Acute Coronary Syndromes. Am J Cardiol 2004;94:873-8.

9. Patel MR, Chen AY, Roe MT, et al. A comparison of acute coronary syndrome care at academic and nonacademic hospitals. Am J Med 2007;120:40-6.

10. Hamm CW, Bassand JP, Agewall S, et al. ESC guidelines for the management of acute coronary syndromes in patients presenting without persistent ST-segment elevation: the Task Force for the 
management of acute coronary syndromes (ACS) in patients presenting without persistent ST-segment elevation of the European Society of Cardiology (ESC). Eur Heart J 2011;32:2999-3054.

11. Anderson JL, Adams CD, Antman EM, et al. ACC/AHA 2007 guidelines for the management of patients with unstable angina/non ST-elevation myocardial infarction: a report of the American College of Cardiology/American Heart Association Task Force on Practice Guidelines (Writing Committee to Revise the 2002 Guidelines for the Management of Patients With Unstable Angina/Non ST-Elevation Myocardial Infarction): developed in collaboration with the American College of Emergency Physicians, the Society for Cardiovascular Angiography and Interventions, and the Society of Thoracic Surgeons: endorsed by the American Association of Cardiovascular and Pulmonary Rehabilitation and the Society for Academic Emergency Medicine. Circulation 2007;116:e148-304.

12. Amsterdam EA, Wenger NK, Brindis RG, et al. 2014 AHA/ACC guideline for the management of patients with non-ST-elevation acute coronary syndromes: a report of the American College of Cardiology/American Heart Association Task Force on Practice Guidelines. Circulation 2014;130:2354-94.

13. Granger CB, Goldberg RJ, Dabbous O, et al. Predictors of hospital mortality in the global registry of acute coronary events. Arch Intern Med 2003;163:2345-53.

14. Fox KA, Dabbous OH, Goldberg RJ, et al. Prediction of risk of death and myocardial infarction in the six months after presentation with acute coronary syndrome: prospective multinational observational study (GRACE). BMJ 2006;333:1091.

15. Antman EM, Cohen M, Bernink PJ, et al. The TIMI risk score for unstable angina/non-ST elevation Ml: a method for prognostication and therapeutic decision making. JAMA 2000;284:835-42.

16. Lagerqvist B, Diderholm E, Lindahl B, et al. FRISC score for selection of patients for an early invasive treatment strategy in unstable coronary artery disease. Heart 2005;91:1047-52.

17. Boersma E, Pieper KS, Steyerberg EW, et al. Predictors of outcome in patients with acute coronary syndromes without persistent ST-segment elevation. Results from an international trial of 9461 patients. The PURSUIT Investigators. Circulation 2000;101:2557-67.

18. Six AJ, Backus BE, Kelder JC. Chest pain in the emergency room: value of the HEART score. Neth Heart J 2008;16:191-6.

19. de Araujo GP, Ferreira J, Aguiar C, et al. TIMI, PURSUIT, and GRACE risk scores: sustained prognostic value and interaction with revascularization in NSTE-ACS. Eur Heart $J$ 2005;26:865-72.

20. Backus BE, Six AJ, Kelder JC, et al. Chest pain in the emergency room: a multicenter validation of the HEART Score. Crit Pathw Cardiol 2010:9:164-9.

21. Yan AT, Yan RT, Tan M, et al. Risk scores for risk stratification in acute coronary syndromes: useful but simpler is not necessarily better. Eur Heart J 2007;28:1072-8.

22. Chew DP, Juergens C, French J, et al. An examination of clinical intuition in risk assessment among acute coronary syndromes patients: observations from a prospective multi-center international observational registry. Int J Cardiol 2014;171:209-16.

23. Manfrini O, Bugiardini R. Barriers to clinical risk scores adoption. Eur Heart J 2007;28:1045-6.

24. Van de Werf F, Ardissino D, Bueno $\mathrm{H}$, et al. Acute coronary syndromes: considerations for improved acceptance and implementation of management guidelines. Expert Rev Cardiovasc Ther 2012;10:489-503

25. Yan AT, Yan RT, Tan M, et al. In-hospital revascularization and one-year outcome of acute coronary syndrome patients stratified by the GRACE risk score. Am J Cardiol 2005;96:913-16.
26. Yan AT, Yan RT, Tan M, et al. Management patterns in relation to risk stratification among patients with non-ST elevation acute coronary syndromes. Arch Intern Med 2007;167:1009-16.

27. Fox KA, Anderson FA Jr, Dabbous $\mathrm{OH}$, et al. Intervention in acute coronary syndromes: do patients undergo intervention on the basis of their risk characteristics? The Global Registry of Acute Coronary Events (GRACE). DHeart 2007:93:177-82.

28. Heras M, Bueno $\mathrm{H}$, Bardaji $\mathrm{A}$, et al. Magnitude and consequences of undertreatment of high-risk patients with non-ST segment elevation acute coronary syndromes: insights from the DESCARTES Registry. Heart 2006;92:1571-6.

29. Lee CH, Tan M, Yan AT, et al. Use of cardiac catheterization for non-ST-segment elevation acute coronary syndromes according to initial risk: reasons why physicians choose not to refer their patients. Arch Intern Med 2008;168:291-6.

30. Motivala AA, Cannon CP, Srinivas VS, et al. Changes in myocardial infarction guideline adherence as a function of patient risk: an end to paradoxical care? J Am Coll Cardiol 2011;58:1760-5.

31. Tra J, Engel J, van der Wulp I, et al. Monitoring guideline adherence in the management of acute coronary syndrome in hospitals: design of a multicentre study. Neth Heart J 2014;22:346-53.

32. VMSzorg. Optimal care in Acute Coronary Syndromes [Original title in Dutch: Optimale zorg in Acute Coronaire Syndromen]. Dutch National Patient Safety Programme. 2010. Http://www.vmszorg.nl/ Themas/ACS

33. van Buuren S, Groothuis-Oudshoorn K. MICE: Multivariate Imputation by Chained Equations in R. J Stat Software 2011;45:1-67.

34. R Core Team. R: a language and environment for statistical computing. 2013. Vienna, Austria, R Foundation for Statistical Computing. http://www.R-project.org

35. McCulloch CE, Searle SR, Neuhaus JM. Generalized, linear, and mixed models. 2nd edn. New Jersey: John Wiley \& Sons, 2008.

36. Kumbhani DJ, Fonarow GC, Cannon CP, et al. Predictors of adherence to performance measures in patients with acute myocardial infarction. Am J Med 2013;126:74.e1-9.

37. Scott IA, Harper CM. Guideline-discordant care in acute myocardial infarction: predictors and outcomes. Med J Aust 2002;177:26-31.

38. Allen LA, O'Donnell CJ, Camargo CA Jr, et al. Comparison of long-term mortality across the spectrum of acute coronary syndromes. Am Heart J 2006;151:1065-71.

39. Tran CT, Laupacis A, Mamdani MM, et al. Effect of age on the use of evidence-based therapies for acute myocardial infarction. Am Heart J 2004; 148:834-41.

40. Ohman EM, Roe MT, Smith SC Jr, et al. Care of non-ST-segment elevation patients: insights from the CRUSADE national quality improvement initiative. Am Heart J 2004;148:S34-9.

41. Haim M, Battler A, Behar S, et al. Acute coronary syndromes complicated by symptomatic and asymptomatic heart failure: does current treatment comply with guidelines? Am Heart $J$ 2004;147:859-64

42. Glickman SW, Boulding W, Staelin R, et al. A framework for quality improvement: an analysis of factors responsible for improvement at hospitals participating in the Can Rapid Risk Stratification of Unstable Angina Patients Suppress Adverse Outcomes with Early Implementation of the ACC/AHA Guidelines (CRUSADE) quality improvement initiative. Am Heart J 2007;154:1206-20.

43. Cannon CP, Hoekstra JW, Larson DM, et al. A report of quality improvement in the care of patients with acute coronary syndromes. Crit Pathw Cardiol 2011;10:29-34.

44. Grol R, Grimshaw J. From best evidence to best practice: effective implementation of change in patients' care. Lancet 2003;362: 1225-30. 